\title{
Microalgae Immobilized by Nanofibrous Web for Removal of Reactive Dyes from Wastewater
}

\author{
Nalan Oya San Keskin, ${ }^{* \dagger, \ddagger, \S}$ Aslı Celebioglu, ${ }^{\S, \|}$ Tamer Uyar, ${ }^{*},, \|$ and Turgay Tekinay ${ }^{*,+, \perp}$ \\ ${ }^{\dagger}$ Polatlı Science and Literature Faculty, Biology Department, Gazi University, Ankara 06900, Turkey \\ ${ }^{\ddagger}$ Life Sciences Application and Research Center, Gazi University, Ankara 06830, Turkey \\ ${ }^{\S}$ UNAM-National Nanotechnology Research Center, and "Institute of Materials Science and Nanotechnology, Bilkent University, \\ Ankara 06800, Turkey \\ ${ }^{\perp}$ Faculty of Medicine, Department of Medical Biology and Genetics, Gazi University, Ankara 06560, Turkey
}

ABSTRACT: In this study, we have developed microalgae immobilized by polysulfone nanofibrous web (microalgae/PSUNFW) for the removal of reactive dyes (Remazol Black 5 (RB5) and Reactive Blue 221 (RB221). Here, an electrospinning technique was used to produce polysulfone nanofibrous web (PSU-NFW) as a free-standing material on which microalgae Chlamydomona reinhardtii was immobilized on PSU-NFW. The decolorization capacities of microalgae/PSU-NFW were significantly higher than that of pristine PSU-NFW. The decolorization rate for RB5 was calculated as $72.97 \pm 0.3 \%$ for microalgae/PSU-NFW, whereas it was $12.36 \pm 0.3 \%$ for the pristine PSU-NFW. In the case of RB221 solution, decolorization rates were achieved as $30.2 \pm 0.23$ and $5.51 \pm 0.4 \%$ for microalgae/PSU-NFW and pristine PSU-NFW, respectively. Reusability tests revealed that microalgae/PSU-NFW can be used in at least three successive decolorization steps in which the decolorization rate of the RB5 was found to be $51 \pm 0.69 \%$ after the third reuse step. These results are promising and therefore suggest that microalgae/PSU-NFW could be applicable for the decolorization of dyes because of their versatility and reusability.

\section{INTRODUCTION}

Intense industrialization and urbanization periods have resulted in a significant amount of waste release into the environment. Common contaminants found in wastewater include biodegradable, volatile, and recalcitrant organic compounds, toxic metals, suspended solids, dyes, microbial pathogens, and parasites. ${ }^{1}$ One of the major causes of environmental pollution is the wastewater of the textile industry. Elimination of dyes from industrial effluents is a major concern today and carries a great deal of importance. Production and usage of 10000 different synthetic dyes and pigments has exceeded 0.7 million tons worldwide. ${ }^{2}$ Anionic (i.e., acid, substantive, and reactive dyes), cationic, and nonionic dyes are the three major classes of industrial dyes. ${ }^{3}$ Because of the various applications of basic and reactive dyes, about $2-50 \%$ of the dyestuff is industrial wastewater and released into the environment. ${ }^{4}$ In general, the concentration of dyes present in textile wastewater is in the range of $10-50 \mathrm{mg} \mathrm{L}^{-1}$, and above the concentration of $1 \mathrm{mg}$ $\mathrm{L}^{-1}$, the dye is visible in the wastewater. ${ }^{5}$ Such dyes can pollute bodies of water and have a profound impact by changing the biological cycles and affecting photosynthesis processes. Furthermore, they can possibly threaten human health because prolonged contact with these products can lead to toxic reactions. ${ }^{6,7}$ Although some technologies exist, such as traditional physical or chemical decolorization including membrane filtration, ${ }^{8}$ ion exchange, ${ }^{9,10}$ ozonation, ${ }^{11}$ and electrochemical destruction, ${ }^{12}$ major disadvantages of these methods are high sludge production, management and disposal problems, high cost, technical limitations, and the fact that they are not environmentally friendly. Therefore, usage of decolorization technologies that are based on the capability of different types of bacterial, fungal, and algal cells to decolorize effluents is accepted because these technologies offer lower cost and environment friendly methods. ${ }^{13-16}$

There are number of studies suggesting that microalgae are ideal biosorbents for wastewater treatment systems because of the ease of growth in simple medium, cheapness, availability, high surface area, and high binding affinity. ${ }^{15}$ However, these biosorbents have several limitations, such as low resistance to chemicals and heat. To overcome this problem, immobilization of microorganisms has been proposed and investigated as a viable means to achieve decolorization and degradation of dyes. ${ }^{17}$ For instance, utilization of immobilized Chlorella vulgaris and Scenedesmus rubescens on a membrane system to remove nitrate from municipal wastewater was found to be efficient. ${ }^{18}$ In addition, Wang et al. ${ }^{19}$ showed that employing immobilized Scenedesmus in calcium alginate as algal sheets is efficient in removal of ammonia nitrogen and orthophosphate from municipal wastewater. There have been few studies on the use of immobilized algae to remove color from dye solutions. For instance, one study reported that degradation of a brown dye by immobilized Chlorella pyrenoidosa in calcium alginate is better than that by free cells. ${ }^{20}$

Electrospinning is a very promising technique for the production of nanofibers owing to its simplicity, versatility, and cost-effectiveness. ${ }^{21-23}$ The unique features (large surfaceto-volume ratios and highly porous structures) of the electrospun nanowebs pave the way for these intriguing materials during use in environmental applications as filter or

Received: March 19, 2015

Revised: $\quad$ May 8, 2015

Accepted: May 11, 2015

Published: May 11, 2015 
membrane systems. ${ }^{24-27}$ Electrospun nanofibers have huge potential to be used as a substrate for various additives, compounds, active agents, and even microorganisms. The integration of microorganisms in electrospun nanofibers is quite applicable for filtration and purification purposes. For instance, there are a few studies reported in the literature relating to incorporation of bacteria in electrospun nanofibers by using different approaches. ${ }^{28-37}$ In one of our recent related studies, Acinetobacter calcoaceticus STB1 cells were immobilized on electrospun cellulose acetate nanofibrous webs (CA-NFW) and used for the removal of ammonium. ${ }^{36}$ In another recent study of ours, three different types of bacteria were immobilized on CA-NFW for removal of methylene blue dye. ${ }^{17}$ There are studies in the literature related to incorporation of microalgae in electrospun nanofibers. ${ }^{38-40}$ For instance, a study by Kim et al. $^{38}$ fabricated electrospun polycaprolactone nanofiber containing Spirulina and tested as a potential matrix for a culture of primary astrocytes. Cha et al. ${ }^{39}$ were prepared silk fibroin nanofiber scaffold containing microalgae Spirulina extract. The functional nanofibers containing microalgae have great potential for the environmental practices. In a study by Eroglu et al. ${ }^{40}$ algal cells were effectively immobilized on electrospun chitosan nanofiber mats for nitrate removal.

Here, Chlamydomonas reinhardtii was chosen as the model organism investigated for physiological, biochemical, and genetic properties of division Chlorophyta. ${ }^{41}$ Reactive Black 5 (RB5) is in the reactive azo dye group extensively used in textile industries producing dyed cotton, woolen, and nylon fabric. ${ }^{42}$ The use of RB5 has negative effects for human life; exposure to this dye may cause allergic reactions and cancer. ${ }^{43}$ Reactive Blue 221 (RB221) has a complex aromatic structure, consisting of monochlorotriazine and sulfato ethyl sulfone derivatives as functional groups; thus, this dye belongs to the group of heterobifunctional reactive dyes. ${ }^{44}$ Polysulfone (PSU) is a membrane material that due to its excellent thermal and mechanical stability as well as its resistance to oxidizing agents has been used as the base of ion-exchange membranes. ${ }^{4-49}$ At present, there is no single process that is capable of treating wastewater. In the literature, adsorption is known as one of the effective and low cost methodology for removal of organic and inorganic pollutants and dyes from water. ${ }^{50}$ For this reason, it will be quite interesting to integrate microalgae cells in an electrospun PSU nanofibrous web to be employed in wastewater treatment. Considering the lack of any reports investigating reactive dye removal by using microalgae integrated in nanofibrous web, to the best of our knowledge this is the first report investigating the dye removal capacity of these biocomposite materials. The aim of this study is to present and investigate an efficient methodology for color treatment of industrial textile wastewater effluent by using a nanofibrous adsorbent based on microalgae immobilized in PSU nanofiber web (PSU-NFW) for the adsorptive and biological removal of RB5 and RB221 as an example of reactive dyes. To maximize the removal capacity of dye through microalgae/PSU-NFW, we have studied decolorization time and different dye concentrations. Finally, the reusability of microalgae/PSU-NFW was tested.

\section{EXPERIMENTAL SECTION}

Contaminant: Reactive Dyes. Two kinds of reactive dye, RB5 and RB221, were obtained from SETAŞ Chemistry Factory (Tekirdag, Turkey). The concentration of dyes in each aqueous solution was measured on a UV-vis spectropho- tometer while taking the absorption at $597 \mathrm{~nm}$. All the chemicals were of highest purity available and were of analytical grade.

Electrospinning of Polysulfone Nanofibrous Web. The homogeneous electrospinning solution was prepared by dissolving polysulfone (PSU, $M_{\mathrm{w}} \approx 60000$, Scientific Polymer Products, Inc.) in N,N-dimethylacetamide/acetone (9:1, (v/v)) (DMAc, Sigma-Aldrich, 99\%; acetone, Sigma-Aldrich, $\geq 99 \%$ (GC)) binary solvent mixture at $32 \%(\mathrm{w} / \mathrm{v})$ polymer concentration. Then, clear solution was inserted in a syringe fitted with metallic needle with a $0.4 \mathrm{~mm}$ inner diameter. The syringe was located horizontally on the syringe pump ((model KDS-101, KD Scientific, USA). The electrode of the highvoltage power supply (Spellman, SL30, USA) was clamped to the metal needle tip, and the plate aluminum collector was grounded. Electrospinning parameters were adjusted as follows: feed rate of solutions $=0.5 \mathrm{~mL} / \mathrm{h}$, applied voltage $=10 \mathrm{kV}$, and tip-to-collector distance $=10 \mathrm{~cm}$. Electrospun nanofibers were deposited on a grounded stationary plate metal collector covered with aluminum foil. The electrospinning apparatus was enclosed in a Plexiglas box, and electrospinning was carried out at $23{ }^{\circ} \mathrm{C}$ at $18 \%$ relative humidity. Collected nanofibers/ nanowebs were dried in a vacuum oven at $50{ }^{\circ} \mathrm{C}$ overnight to remove the residual solvent.

Growth and Immobilization of Microalgae Strain. C. reinhardtii was obtained from Life Sciences Application and Research Center, culture collection of Sustainable Energy Lab, Gazi University. Cells were grown in tris-acetate-phosphate (TAP) medium and cultivated at $23{ }^{\circ} \mathrm{C}$ under continuous illumination $\left(150 \mu\right.$ moles photons $\left.\mathrm{m}^{-2} \mathrm{~s}^{-1}\right)$. C. reinhardtii biomass was measured by counting the number of cells by optical microscopy (Olympus, Japan) using a Neubauer Hemocytometer (Germany). Then, $1 \mathrm{~mL}$ of algae solution containing $\sim 7 \times 10^{6}$ cells $\mathrm{mL}^{-1}$ was placed onto $20 \mathrm{mg}$ of UVsterilized PSU-NFW and incubated at $23{ }^{\circ} \mathrm{C}$ in a rotary shaker at $100 \mathrm{rpm}$ for 10 days to allow sufficient attachment of algae cells to the surface of the web. After attachment, microalgae/ PSU-NFW samples was quantified using a multistep process of cell removal by sonication at a frequency of $40 \mathrm{kHz}$ (Branson Ultrasonic Cleaner; Branson Ultrasonics, Danbury, CT) for 30 min and vortexing for $30 \mathrm{~s}$. After the detachment process, cells counted using Neubauer Hemocytometer.

Characterization of Polysulfone Nanofibrous Web. The morphologies of pristine PSU-NFW and microalgae/PSUNFW were investigated by scanning electron microscope (SEM, Quanta 200 FEG, FEI) while the accelerating voltage was changed between 3 and $5 \mathrm{kV}$. Samples were washed twice with PBS buffer; then, air-dried samples were coated with approximately $5 \mathrm{~nm}$ layer of gold-palladium before imaging.

Raman spectra were recorded on a WITec alpha300 S Confocal Raman spectrometer for confirmation of microalgae attachment. The near-infrared $785 \mathrm{~nm}$ line was used for excitation. For all presented spectra, the laser power on the sample did not exceed $3 \mathrm{~mW}$, and 10 scans were collected in 15 s. All spectra were recorded with a spectral resolution of 4 $\mathrm{cm}^{-1}$.

Batch Decolorization Operation. To evaluate the effects of operation factors on the efficiency of decolorization, the batch decolorization experiments were carried out at different contact time (0-14 days) and initial dye concentrations (10, 25 , and $50 \mathrm{ppm})$. After the inoculation process, aliquots $(4 \mathrm{~mL})$ of the culture media were withdrawn and centrifuged at 10000 $\mathrm{g}$ for $10 \mathrm{~min}$ to separate the microalgae mass. The supernatant 
was used for analysis of decolorization, and all the experiments were repeated in triplicate. Absorbance of the supernatant withdrawn at different time intervals were measured at the absorbance maximum wavelength for the dye RB5 and RB221 $\left(\lambda_{\max }=597 \mathrm{~nm}\right)$ on a Shimadzu spectrophotometer. Decolorization was determined by absorbance reduction.

The percentage of decolorization was calculated from the difference between initial and final values using the following formula:

$$
\begin{aligned}
& \text { \% Decolorization } \\
& =\frac{\text { Initial absorbance value }- \text { final absorbance value }}{\text { Initial absorbance value }} \\
& \quad \times 100
\end{aligned}
$$

Uninoculated Erlenmeyer flasks containing dyes were used as control samples to observe any reactions of the media with the dye. Each of these experiments and the measurements described below follow the daily changes in the samples throughout the incubation period. Each experiment consisted of triplicate batches. Each result is an average of three parallel replicates. The \pm indicates standard deviation among the replicates.

Decolorization Test. To determine the effect of contact time, $20 \mathrm{mg}$ of microalgae/PSU-NFW were incubated into 100 $\mathrm{mL}$ of media containing $10 \mathrm{mg} \mathrm{L}^{-1} \mathrm{RB} 5$ and $\mathrm{RB} 221$ dye solution at $\mathrm{pH} 6$ and placed on a incubator at $23{ }^{\circ} \mathrm{C}$ in a rotary shaker at $100 \mathrm{rpm}$ for different times $(1,2,3,5,7$, and 14 days). The same dye concentration $\left(10 \mathrm{mg} \mathrm{L}^{-1}\right)$ is employed to obtain positive control with free microalgae cells, negative control with pristine PSU-NFW, and experimental set with microalgae/PSU-NFW.

Textile processing wastewater with dye contents in the range of $10-200 \mathrm{mg} \mathrm{L}^{-1}$ is highly colored. For this reason, initial dye concentrations were adjusted to 10,25 , and $50 \mathrm{mg} \mathrm{L}^{-1}$ to represent low, medium, and high concentrations of dye. Microalgae/PSU-NFW were cultivated for 14 days in a conical flask containing $100 \mathrm{~mL}$ of TAP medium with dyes RB5 and RB221 at a concentration of 10,25 , and $50 \mathrm{mg} \mathrm{L}^{-1}$ separately to study the effect of increasing dye concentration on percentage dye decolorization. All determinations were made daily during the incubation.

Reusability Experiments for Microalgae/PSU-NFW. Decolorization studies were performed three times to assess the reusability of the microalgae/PSU-NFW for an initial concentration of $10 \mathrm{mg} \mathrm{L}^{-1}$ for RB5 and RB221 dyes. Before each cycle, microalgae/PSU-NFW pieces were washed three times with sterile PBS buffer. Dye decolorization experiments were performed at $100 \mathrm{rpm}$ and $23{ }^{\circ} \mathrm{C}$ for 14 days after each washing step, for a total of three cycles. Dye concentrations were measured at $0 \mathrm{~h}$ and 14 days. Each cycle was terminated after 14 days of total incubation, and washing steps were repeated before the initiation of the next cycle. All tests were done in triplicate.

Statistical Analysis. Student's $t$ test was applied for statistical analyses. Analyses were done by using the software Minitab, version 13.2 (Minitab Inc., USA), at a 0.05 level of probability.

\section{RESULTS AND DISCUSSION}

Immobilization of $C$. reinhardtii on Polysulfone Nanofibrous Web. Several studies have been reported on wastewater treatment by using microalgae cultures inside alginate beads, porous glass, and several synthetic polymers. ${ }^{51,52}$ However, these materials have limitations, e.g., encapsulating materials having volume/surface ratios usually orders of magnitude larger than thin films. As a consequence, algal viability is mostly reported to decrease, which relates to the need for the nutrients or reactants to diffuse far into the material to reach the algal cells. ${ }^{53}$ In this study, the electrospun nanofibrous web as the matrix for immobilizing the algal cells is used to overcome aforementioned problems.

Figure 1a shows the schematic representation of the electrospinning process for polysulfone nanofibrous web
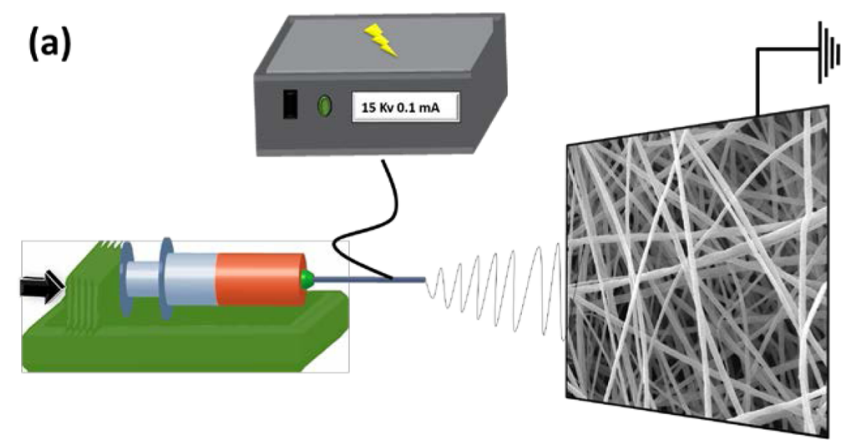

(b)

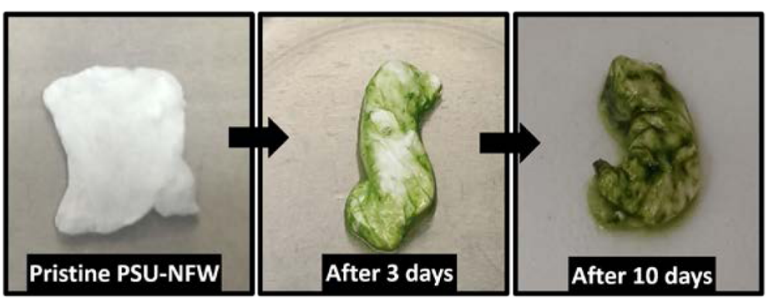

(c)
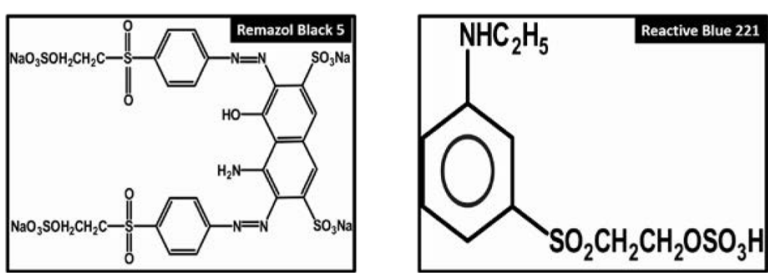

Figure 1. (a) Schematic representation of the electrospinning process for PSU-NFW. (b) Photos of attachment of free microalgae cells on PSU-NFW for 3 and 10 day attachment processes. (c) Chemical structures of Remazol Black 5 (RB5) and Reactive Blue 221 (RB221).

(PSU-NFW). Figure $1 \mathrm{~b}$ shows the photos of microalgae cells attached to the surface of PSU-NFW after 3 days and after 10 days from the start of the growth experiments. As seen in Figure $1 \mathrm{~b}$, increasing green color on the surface is seen because of the increased concentration of microalgae cells on the PSUNFW with respect to time. Figure 1c shows the chemical structures of RB5 and RB221.

Figure 2a shows the SEM image of the nanofibrous structure of the electrospun PSU-NFW having uniform and bead-free morphology. Moreover, SEM analysis was performed after 10 days of incubation for the microalgae attachment to PSU-NFW, shown in Figure 2b,c. After 10 days, C. reinhardtii were strongly attached onto PSU-NFW. This type of attachment was found to be adequate for further studies, and dye decolorization experiments were performed with microalgae/PSU-NFW at this stage. In addition, according to counting experiments, $1 \mathrm{~mL}$ of algae solution, containing $\sim 7 \times 10^{6}$ cells $\mathrm{mL}^{-1}$, was used for the attachment. After the detachment process, $\sim 5 \times 10^{6}$ cells 

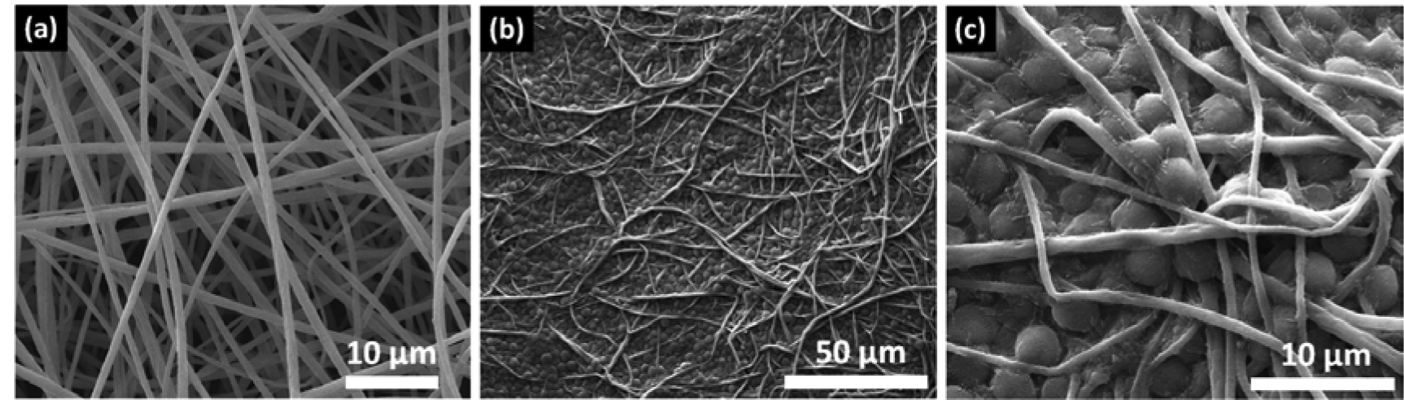

Figure 2. Representative SEM images of (a) pristine PSU-NFW and (b and c) microalgae/PSU-NFW (under different magnifications).
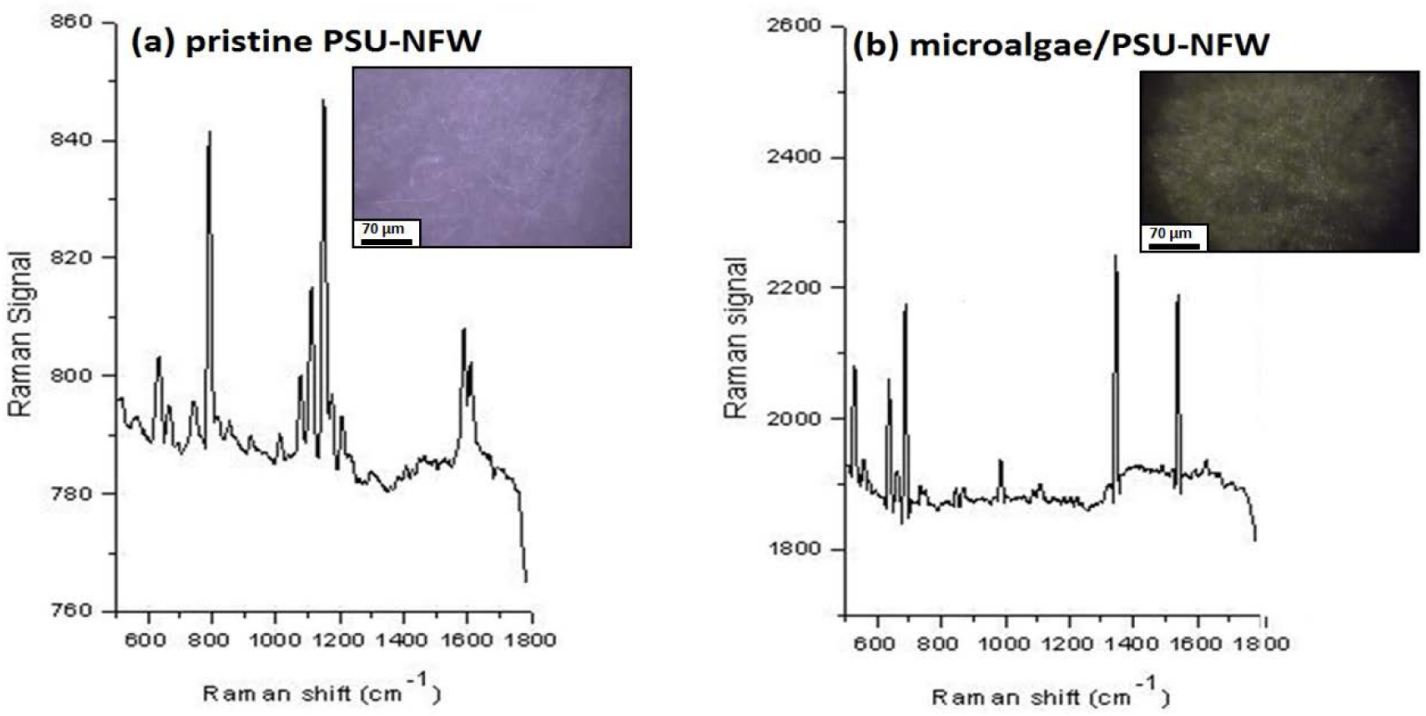

Figure 3. Raman spectra of (a) pristine PSU-NFW and (b) microalgae/PSU-NFW after 14 day attachment process. Insets show the microscope image of the corresponding material.

$\mathrm{mL}^{-1}$ per volume of web was counted. As a result, $\sim 80 \%$ microalgae was successfully attached to PSU-NFW.

It is known that Raman spectroscopy could be a very informative and convenient tool for studying the structure of polymers ${ }^{54}$ and microorganisms. ${ }^{55,56}$ Raman spectra of pristine PSU-NFW (Figure 3a) and microalgae/PSU-NFW (Figure 3b) with main Raman shifts and assignments of the Raman bands are given in Figure 3. Moreover, the insets show the microscope image of pristine PSU-NFW and microalgae/ PSU-NFW, respectively. In the Raman spectrum of the pristine PSU-NFW, the band around $788 \mathrm{~cm}^{-1}$ is associated with the presence of $\mathrm{C}-\mathrm{S}-\mathrm{C}$ symmetric stretching. Also, the peaks around 1073, 1108, 1149, and $1204 \mathrm{~cm}^{-1}$ are due to the presence of symmetric $\mathrm{SO}_{2}$ stretching, asymmetric $\mathrm{SO}_{2}$ stretching, symmetric $\mathrm{C}-\mathrm{O}-\mathrm{C}$ stretching, and asymmetric $\mathrm{C}-\mathrm{O}-\mathrm{C}$ stretching, respectively. In the Raman spectrum taken from the microalgae/PSU-NFW, the presence of dominant polysaccharide, glycoproteins, and lipid frequencies around $1000-1500 \mathrm{~cm}^{-1}$ was identified. In addition, a specific $\beta$ carotene peak ( $\mathrm{C}=\mathrm{C}$ stretching) at $1517 \mathrm{~cm}^{-1}$ was seen, ${ }^{57}$ and results confirmed that $C$. reinhardtii were attached successfully on the PSU-NFW.

Contact time is one of the important parameters to successfully adsorb the pollutants for practical application. The effects of contact time on the decolorization process were studied in the time range of $1-14$ days at $10 \mathrm{mg} \mathrm{L}^{-1}$ initial RB5 and $\mathrm{RB} 221$ at $\mathrm{pH} 6.0$ at $23{ }^{\circ} \mathrm{C}$. The RB5 and RB221 decolorization performance of pristine PSU-NFW, free microalgae cells, and microalgae/PSU-NFW after certain time periods $(1,2,3,5,7$, and 14 days) are shown in Figure 4. During the experiments, there was no reaction between media content and dyes. As clearly seen in Figure 4, the decolorization increased during the first 14 days: the dye decolorization of RB5 for microalgae/PSU-NFW was $73.0 \pm 0.3 \%$ within 14 days when compared to $68.8 \pm 0.3$ and $12.4 \pm 0.3 \%$ for free microalgae cells and pristine PSU-NFW, respectively. On the other hand, the decolorization efficiency for RB221 was found to be low when compared to RB5 dye. In media with RB221, the maximum dye decolorization for microalgae/PSU-NFW was $30.2 \pm 0.2 \%$. The decolorization of RB221 was $28.6 \pm 0.2 \%$ for free microalgae cells and $5.5 \pm 0.4 \%$ for pristine PSU-NFW. This variation in the decolorization of different dyes might be attributable to the structural diversity of the dyes. Statistical analyses revealed that there is no statistically significant difference between free microalgae and microalgae/PSUNFW decolorization rates $(P>0.05)$. Results of this study revealed that 14 days of contact time is required to achieve maximum decolorization. Our results showed that the decolorization efficiency of microalgae/PSU-NFW for RB5 and RB221 dyes was slightly better than the free microalgae cells, and it was much better than the pristine PSU-NFW. So, the decolorization performance of microalgae/PSU-NFW is quite impressive and has certain advantages over using free microalgae cells. First, microalgae/PSU-NFW can be reusable, 
(a)

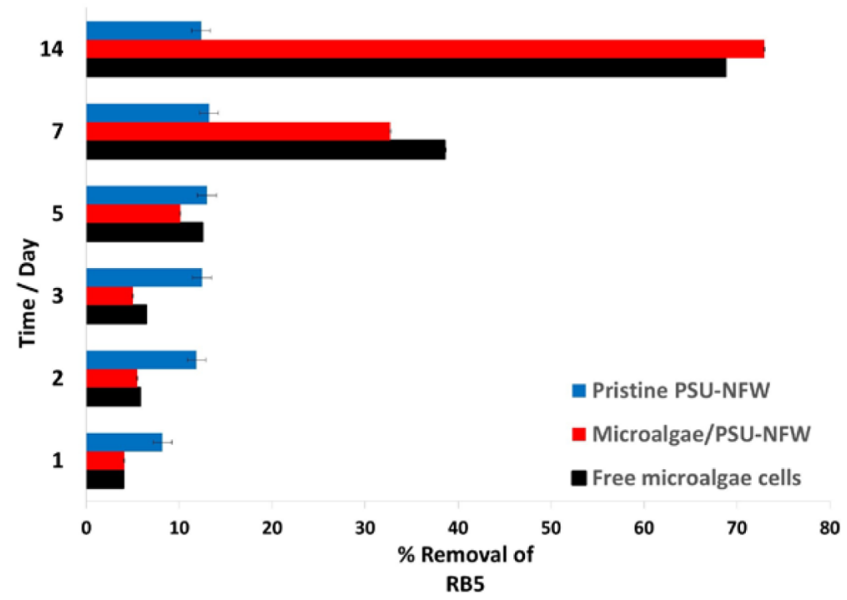

(b)

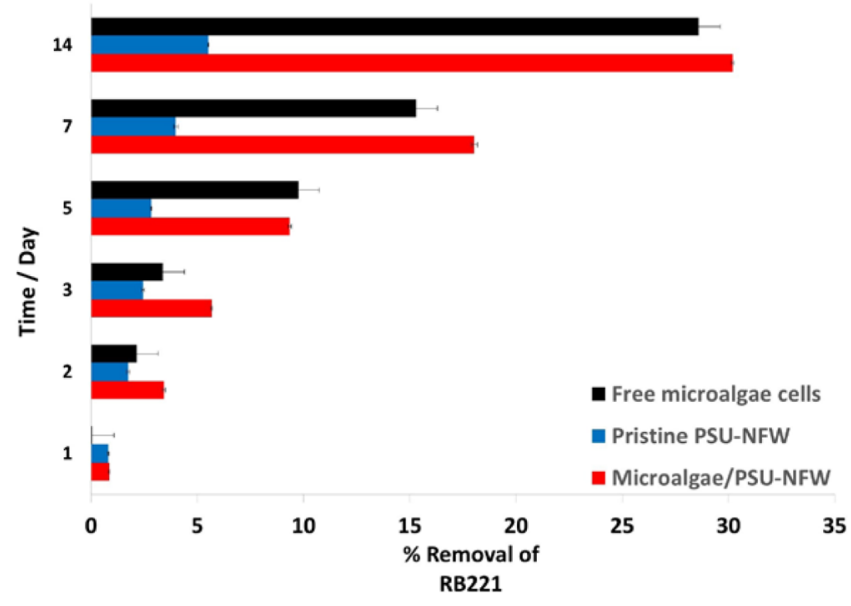

Figure 4. Effect of contact time on the decolorization yield microalgae/PSU-NFW in $10 \mathrm{mg} \mathrm{L}^{-1}$ (a) RB5 and (b) RB221 (pH 6 ; $T=23{ }^{\circ} \mathrm{C}$; stirring rate $\left.=100 \mathrm{rpm}\right)$. Error bars represent the means of three independent replicates.

whereas free microalgae cells dispersed throughout the medium/wastewater are quite difficult to harvest, dewater, and reuse in another portion of dye-contaminated wastewater. Second, microalgae/PSU-NFW occupies less space and requires a smaller volume of growth medium when compared to stock solutions of free microalgae cells. So, microalgae/PSUNFW would be more practical and cost-effective for treatment of dye-contaminated wastewater.

The influence of initial dye concentration on the decolorization process of RB5 and RB221 reactive dyes by microalgae/PSU-NFW was investigated by using various dye concentrations; 10,25 , and $50 \mathrm{mg} \mathrm{L^{-1 }}$. The results were obtained during 14 days of incubation. As given in Figure 5a, $73.0 \pm 0.3 \% \mathrm{RB} 5$ decolorization was achieved at $10 \mathrm{mg} \mathrm{L}^{-1}$. For $25 \mathrm{mg} \mathrm{L}^{-1}$ dye concentration, the decolorization capacity of RB5 by microalgae/PSU-NFW was $47.7 \pm 0.2 \%$. When dye concentration was increased up to $50 \mathrm{mg} \mathrm{L}^{-1}$, the decolorization capacity was $18.7 \pm 0.4 \%$. It was noted that more or less the same amount of RB5 dye $\left(\sim 7.3-11.9 \mathrm{mg} \mathrm{L}^{-1}\right)$ was removed by microalgae/PSU-NFW from the solutions having dye concentrations of 10,25 , and $50 \mathrm{mg} \mathrm{L}^{-1}$. At the end of the experiments, the $\mathrm{pH}$ value was checked, and a slight decrease from 6.0 to 5.85 was observed. Moreover, the
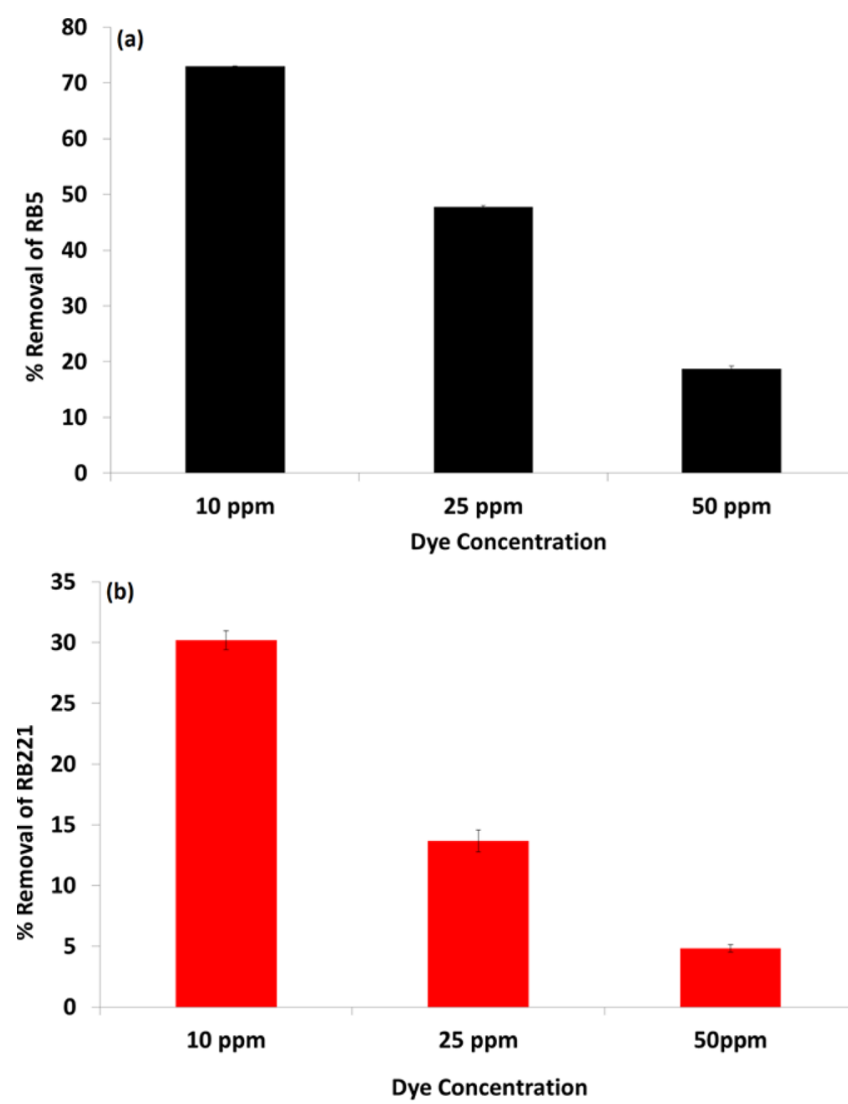

Figure 5. Effect of initial dye concentration on the decolorization yield of the microalgae/PSU-NFW polysulfone nanofibrous web on the 10 $\mathrm{mg} \mathrm{L}^{-1}$ (a) RB5 and (b) RB221 (pH 6; $T=23{ }^{\circ} \mathrm{C}$; stirring rate $=100$ $\mathrm{rpm})$. Error bars represent the means of three independent replicates.

structural morphology of the microalgae/PSU-NFW was investigated by SEM after 14 days decolorization process. Figure $6 \mathrm{a}, \mathrm{b}$ confirmed that the nanofibrous structure was preserved and that microalgae were retained and still have a proper shape when subjected to RB5 solution after 14 days. In the case of the RB221 dye decolorization by microalgae/PSUNFW (Figure $5 b$ ), the decolorization capacity was found to be $30.2 \pm 0.2 \%$ in the concentration of $10 \mathrm{mg} \mathrm{L}^{-1}$ dye concentration sample. For $25 \mathrm{mg} \mathrm{L}^{-1}$ dye concentration, the

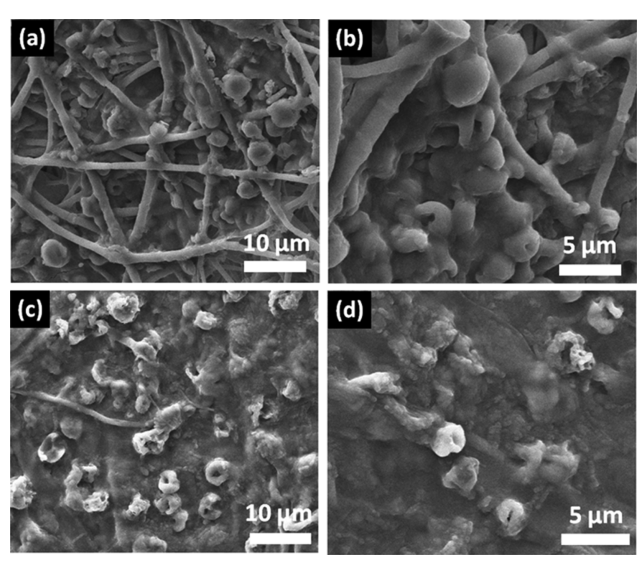

Figure 6. Representative SEM images of microalgae/PSU-NFW after 14 day decolorization process for RB5 under (a) low and (b) high magnification and for RB221 under (c) low and (d) high magnification. 
decolorization capacity of RB221 by microalgae/PSU-NFW was $13.6 \pm 0.9 \%$. In the case of $50 \mathrm{mg} \mathrm{L}^{-1} \mathrm{RB} 221$, the removal of RB221 dye was $4.8 \pm 0.3 \%$. As a result, approximately the same amount of RB221 dye $\left(\sim 2.4-3.0 \mathrm{mg} \mathrm{L}^{-1}\right)$ was removed by microalgae/PSU-NFW. It was observed that the $\mathrm{pH}$ value of the solution also decreased from 6.0 to 3.45 . The decrease could be attributed to the presence of excess $\mathrm{H}^{+}$, making adsorption less favorable. Furthermore, at $\mathrm{pH}$ below this point, microalgae growth decreased because of the increase in the toxicity. SEM analysis (Figure $6 c, d$ ) confirmed that circular shapes of the microalgae cannot be observed because of severe effect of the RB221. ${ }^{58,59}$

Reusability Results. From the viewpoint of biotreatment studies, it was essential to monitor the reusability of the strain. The dye decolorization capability of microalgae/PSU-NFW was tested for three cycles of reuse (Figure 7). As seen in Figure 7,

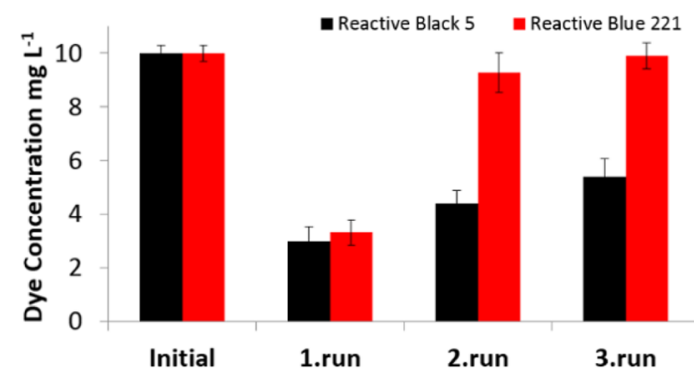

Figure 7. Reusability test results of the three cycles of RB5 and RB221 dye decolorization experiments at the initial dye concentration of 10 $\mathrm{mg} \mathrm{L^{-1 }}$. Error bars represent the means of three independent replicates.

the RB5 and RB221 decolorization efficiency was decreased for higher cycles. The decline in the removal efficiency might be due to detachment of the immobilized bacteria in the washing step and dye toxicity to microalgae cells. After the first cycles of regeneration, favorable percent removal of dyes was observed as $60 \pm 0.5$ and $15.6 \pm 0.7 \%$ for RB5 and RB221, respectively. For the third regeneration cycle, the reactive dye decolorization dropped because of decreasing number of algae cells to $51.0 \pm$ 0.7 and $8.5 \pm 0.5 \%$ for RB5 and RB221, respectively. For practical applications, the level of reusability is an important issue. $51.0 \pm 0.7 \%$ of the dye decolorization capacity was obtained for the third cycle for RB5, which suggests that microalgae/PSU-NFW can sustain their decolorization capacity under several cycles of reuse and may be utilized repeatedly for dye decolorization of wastewater in textile and paint industry.

\section{CONCLUSIONS}

Electrospun PSU-NFW was chosen as a suitable support for microalgae growth for preparation of biocomposite capable of decolorization of reactive dyes in wastewater. RB5 and RB221 reactive dyes were chosen as the target contaminant because they are extensively used in textile industry. The microalgae/ PSU-NFW was found to be quite successful for the removal of these reactive dyes from the aqueous environment. In fact, our results demonstrated that the decolorization capacity of microalgae/PSU-NFW for RB5 and RB221 dyes was even better than that of the free microalgae cells, and it was much better than that of the pristine PSU-NFW. The reusability of microalgae/PSU-NFW was determined after three cycles, and $\sim 50 \%$ of the RB5 dye decolorization capacity was obtained at the end of the third cycle, suggesting that these microalgae/
PSU-NFW can be reused and may be utilized repeatedly for dye decolorization in industrial wastewater. So, the decolorization performance of microalgae/PSU-NFW is quite notable and has several advantages over using free microalgae cells. Because of its simple, reusable, and nanoporous characteristics, the microalgae/PSU-NFW biocomposite can be a promising membrane material for industrial wastewater treatment.

\section{AUTHOR INFORMATION}

\section{Corresponding Authors}

*Tel.: +90 (312) 484 6270. Fax: +90 (312) 484 6271. E-mail: oyasan@gazi.edu.tr.

*Tel.: +90 (312) 290 3571. Fax: +90 (312) 266 4365. E-mail: tamer@unam.bilkent.edu.tr.

*Tel.: +90 (312) 484 6270. Fax: +90 (312) 484 6271. E-mail: ttekinay@gazi.edu.tr.

\section{Notes}

The authors declare no competing financial interest.

\section{ACKNOWLEDGMENTS}

The Scientific and Technological Research Council of Turkey (TUBITAK, project \#114Y264) is acknowledged for funding the research. T.U. also acknowledges The Turkish Academy of Sciences - Outstanding Young Scientists Award Program (TUBA-GEBIP) for partial funding of the research. A.C. acknowledges TUBITAK (project \#113Y348) for a postdoctoral fellowship.

\section{REFERENCES}

(1) Gurses, C.; Dogar, M.; Yalcın, M.; Acikyildiz, R.; Bayrak Karaca, $\mathrm{S}$. The adsorption kinetics of the cationic dye, Methylene Blue, onto clay. J. Hazard. Mater. 2006, 131, 217.

(2) Chen, K. C.; Huang, W. T.; Wu, J. Y.; Houng, J. Y. Microbial decolorization of azo dyes by Proteus mirabilis. J. Ind. Microbiol. Biotechnol. 1999, 23, 686.

(3) Vasconcelos, H. L.; Fávere, V. T.; Gonçalves, N. S.; Laranjeira, M. C. M. Chemically modifiedorganic/inorganic nanoporous composite particles for the adsorption of Reactive Black 5 from aqueous solution. React. Funct. Polym. 2007, 67, 1052.

(4) Atafar, Z.; Mesdaghinia, A.; Nouri, J.; Homaee, M.; Yunesian, M. Effect of fertilizer application on soil heavy metal concentration. Environ. Monit. Assess. 2010, 160, 83.

(5) Lazaridis, N. K.; Karapantsios, T. D.; Georgantas, D. Kinetic analysis for the removal of a reactive dye from aqueous solution onto hydrotalcite by adsorption. Water Res. 2003, 37, 3023.

(6) Pavan, F. A.; Dias, S. L. P.; Lima, E. C.; Benvenutti, E. V. Removal of Congo red from aqueous solution by anilinepropylsilica xerogel. Dyes Pigm. 2008, 76, 64.

(7) Shen, D.; Fan, J.; Zhou, W.; Gao, B.; Yue, Q.; Kanga, Q. Adsorption kinetics and isotherm of anionic dyes onto organobentonite from single and multisolute systems. J. Hazard. Mater. 2009, $172,99$.

(8) Zheng, Y.; Yao, G.; Cheng, Q.; Yu, S.; Liu, G. C. Positively charged thin-film composite hollow fiber nanofiltration membrane for the removal of cationic dyes through submerged filtration. Desalination 2013, 328, 42.

(9) Greluk, M.; Hubicki, Z. Evaluation of polystyrene anion exchange resin for removal of reactive dyes from aqueous solutions. Chem. Eng. Res. Des. 2013, 91, 1343.

(10) Labanda, J.; Sabaté, J.; Llorens, J. Experimental and modeling study of the adsorption of single and binary dye solutions with an ionexchange membrane adsorber. Chem. Eng. J. 2011, 166, 536.

(11) Wijannarong, S.; Aroonsrimorakot, S.; Thavipoke, P.; Kumsopa, C.; Sangjan, S. Removal of reactive dyes from textile dyeing industrial effluent by ozonation process. APCBEE Proc. 2013, 5, 279. 
(12) Bandara, J.; Wansapura, P. T.; Jayathilaka, S. P. B. Indium tin oxide coated conducting glass electrode for electrochemical destruction of textile colorants. Electrochim. Acta 2007, 52, 4161.

(13) Acuner, E.; Dilek, F. B. Treatment of tectilon yellow $2 \mathrm{G}$ by Chlorella vulgaris. Process Biochem. (Oxford, U.K.) 2004, 39, 623.

(14) Daneshvar, N.; Ayazloo, M.; Khataee, A. R.; Pourhassas, M. Biological decolorization of dye solution containing Malachite Green by microalgae Cosmarium sp. Bioresour. Technol. 2007, 98, 1176.

(15) Ives, K. J. The significance of surface electric charge on algae in water purification Journal of biochemical and microbiological technology and engineering. J. Biochem. Microbiol. Technol. Eng. 2004, 1, 37.

(16) Jadhav, J. P.; Parshetti, G. K.; Kalme, S. D.; Govindwar, S. P. Decolourization of azo dye methyl red by Saccharomyces cerevisiae MTCC463. Chemosphere 2007, 68, 394.

(17) San, N. O.; Celebioglu, A.; Tümtaş, Y.; Uyar, T.; Tekinay, T. Reusable bacteria immobilized electrospun nanofibrous webs for decolorization of methylene blue dye in wastewater treatment. RSC Adv. 2014, 4, 32249.

(18) Shi, J.; Podola, B.; Melkonian, M. Removal of nitrogen and phosphorus from wastewater using microalgae immobilized on twin layers: An experimental study. J. Appl. Phycol. 2007, 19, 417.

(19) Wang, B.; Wang, Q.; Zhang, S.; Zhao, B.; Zhang, E. Ammonianitrogen and orthophosphate removal by immobilized Scenedesmus sp. isolated from municipal wastewater for potential use in tertiary treatment. Bioresour. Technol. 2008, 99, 3787.

(20) Huang, G.; Sun, H.; Cong, L. L. Study on the physiology and degradation of dye with immobilized algae. Artif. Cells, Blood Substitutes, Immobilization Biotechnol. 2000, 28, 347.

(21) Greiner, A.; Wendorff, J. Electrospinning: a fascinating method for the preparation of ultrathin fibers. Angew. Chem., Int. Ed. 2007, 46, 5670 .

(22) Ramakrishna, S.; Fujihara, K.; Teo, W.; Lim, T.; Ma, Z. An Introduction to Electrospinning and Nanofibers; World Scientific Publishing Company: Singapore, 2005.

(23) Wendorff, J. H.; Agarwal, S.; Greiner, A. Electrospinning: materials, processing, and applications; Wiley- $\mathrm{VCH}$ : Weinheim, Germany, 2012.

(24) Gensheimer, M.; Brandis-Heep, A. S.; Agarwal, R; Thauer, K.; Greiner, A. Polymer/bacteria composite nanofiber nonwovens by electrospinning of living bacteria protected by hydrogel microparticles. Macromol. Biosci. 2011, 11, 333.

(25) Ramakrishna, S.; Fujihara, K.; Teo, W. E.; Yong, T.; Ma, Z.; Ramaseshan, R. Electrospun nanofibers: solving global issues. Mater. Today. 2006, 9, 40.

(26) Uyar, T.; Havelund, R.; Hacaloglu, J.; Besenbacher, F.; Kingshott, P. Functional electrospun polystyrene nanofibers incorporating alpha, beta and gamma cyclodextrins: Comparison of molecular filter performance. ACS Nano 2010, 4, 5121.

(27) Yoon, K.; Hsiao, B.; Chu, B. Functional nanofibers for environmental application. J. Mater. Chem. 2008, 18, 5326.

(28) Fung, W. Y.; Yuen, K. H.; Liong, M. T. Agrowaste-based nanofibers as a probiotic encapsulant: fabrication and characterization. J. Agric. Food. Chem. 2011, 59, 8140.

(29) Gensheimer, M.; Becker, M.; Brandis-Heep, A.; Wendorff, J. H.; Thauer, R. K.; Greiner, A. Encapsulation of bacterial cells in electrospun microtubes. Adv. Mater. 2007, 19, 2480.

(30) Klein, S.; Kuhn, J.; Avrahami, R.; Tarre, S.; Beliavski, M.; Green, M.; Zussman, E. Encapsulation of bacterial cells in electrospun microtubes. Biomacromolecules 2009, 10, 1751.

(31) Korehei, R.; Kadla, J. F. Encapsulation of T4 bacteriophage in electrospun poly(ethylene oxide)/cellulose diacetate fibers. Carbohydr. Polym. 2014, 100, 150.

(32) López-Rubio, A.; Sanchez, E.; Sanz, Y.; Lagaron, J. M. Encapsulation of living Bifidobacteria in ultrathin $\mathrm{PVOH}$ electrospun fibers. Biomacromolecules 2009, 10, 2823.

(33) López-Rubio, A.; Sanchez, E.; Wilkanowicz, S.; Sanz, Y.; Lagaron, J. M. Electrospinning as a useful technique for the encapsulation of living bifidobacteria in food hydrocolloids. Food Hydrocolloids 2012, 28, 159.

(34) Raveendran, S.; Dhandayuthapani, B.; Nagaoka, Y.; Yoshida, Y.; Maekawa, T.; Kumar, D. S. Bacterial exopolysaccharide based nanoparticles for sustained drug delivery, cancer chemotherapy and bioimaging. Carbohydr. Polym. 2013, 92, 1225.

(35) Salalha, W.; Kuhn, J.; Dror, Y.; Zussman, E. Encapsulation of bacteria and viruses in electrospun nanofibers. Nanotechnology 2006, 17,4675 .

(36) Sarioglu, O. F.; Yasa, O.; Celebioglu, A.; Uyar, T.; Tekinay, T. Efficient ammonium removal from aquatic environments by Acinetobacter calcoaceticus STB1 immobilized on an electrospun cellulose acetate nanofibrous web. Green Chem. 2013, 15, 2566.

(37) Vajdai, A.; Szabó, B.; Süvegh, K.; Zelkó, R.; Újhelyia, G. Tracking of the viability of Stenotrophomonas maltophilia bacteria population in polyvinylalcohol nanofiber webs by positron annihilation lifetime spectroscopy. Int. J. Pharm. 2012, 429, 135.

(38) Kim, M. S.; Park, S. J.; Gu, B. K.; Kim, C. H. Polycaprolactonechitin nanofibrous mats as potential scaffolds for tissue engineering. $J$. Nanomater. 2012, 635212.

(39) Cha, B. G.; Kwak, H. W.; Park, A. R.; Kim, S. H.; Park, S. Y.; Kim, H. J.; Kim, I. S.; Lee, K. H.; Park, Y. H. Structural characteristics and biological performance of silk fibroin, nanofiber containing microalgae spirulina extract. Biopolymers 2014, 101, 307.

(40) Eroglu, E.; Agarwal, V.; Bradshaw, M.; Chen, X.; Smith, S. M.; Raston, C.; Swaminathan, I. K. Nitrate removal from liquid effluents using microalgae immobilized on chitosan nanofiber mats. Green Chem. 2012, 14, 2682.

(41) Harris, E. H. The Chlamydomonas Sourcebook: A Comprehensive Guide to Biology and Laboratory Use; Academic Press Inc: San Diego, CA, 1989.

(42) Hadibarata, T.; Adnan, L. A.; Yusoff, A. R. M.; Yuniarto, A.; Rubiyatno, Z. M. M. F. A.; Khudhair, A. B.; The, Z. C.; Naser, M. A. Microbial decolorization of an azo dye Reactive Black 5 using white-rot fungus Pleurotus eryngii F032. Water, Air, Soil Pollut. 2013, 224, 1586.

(43) Usha, M. S.; Sasirekha, B.; Bela, R. B.; Devi, S.; Kamalini, C.; Manasa, G. A.; Neha, P. M. Optimization of Reactive Black 5 dye and Reactive Red 120 dye degradation. J. Chem. Pharm. Res. 2011, 3, 450.

(44) Libra, J. A.; Brocherst, M.; Vigelahn, L.; Storm, T. Two stage biological treatment of a diazo reactive textile dye and the fate of the dye metabolites. Chemosphere 2004, 56, 167.

(45) Cui, W.; Kerres, J.; Eigenberger, G. Development and characterization of ion-exchange polymer blend membranes. Sep. Purif. Technol. 1998, 14, 145.

(46) Eyal, A.; Kedem, O. J. Nitrate-selective anion-exchange membranes. J. Membr. Sci. 1988, 38, 101.

(47) Hao, J. H.; Chen, C. X.; Li, L.; Yu, L. X.; Jiang, W. J. J. Preparation of bipolar membranes (I). J. Appl. Polym. Sci. 2001, 80, 1658.

(48) Hwang, G. J.; Ohya, H. J. Preparation of anion-exchange membrane based on block copolymers: Part 1 . Amination of the chloromethylated copolymers. J. Membr. Sci. 1998, 140, 195.

(49) Kerres, J.; Cui, W.; Disson, R.; Neubrand, W. Development and characterization of cross-linked ionomer membranes based upon sulfinated and sulfonated PSU-cross-linked PSU blend membranes by alkylation of sulfinate groups with dihalogenoalkanes. J. Membr. Sci. 1998, 139, 211.

(50) Al-Degs, Y.; Khraisheh, M. A. M.; Allen, S. J.; Ahmad, M. N. A. Sorption behaviour of cationic and anionic dyes from aqueous solution on different types of activated carbons. Sep. Sci. Technol. 2001, 36, 91.

(51) de-Bashan, L. E.; Hernandez, J. P.; Morey, T.; Bashan, Y. Microalgae growth-promoting bacteria as "helpers" for microalgae: a novel approach for removing ammonium and phosphorus from municipal wastewater. Water Res. 2004, 38, 466.

(52) Vílchez, C.; Garbayo, I.; Lobato, M. V.; Vega, J. M. Microalgaemediated chemicals production and wastes removal. Enzyme Microb. Technol. 2007, 20, 562.

(53) Hameed, M. S. A.; Ebrahim, O. H. Biotechnological potential uses of immobilized algae. Int. J. Agric. Biol. 2007, 9, 183. 
(54) Petreska, G. S.; Blazevska-Gilev, J.; Fajgar, R.; Tomovska, R. Surface-Enhanced Raman Scattering activity of Ag/graphene/polymer nanocomposite films synthesized by laser ablation. Thin Solid Films 2014, 564, 115.

(55) Wei, X.; Jie, D.; Cuello, J. J.; Johnson, D. J.; Qiu, Z.; He, Y. Microalgal detection by Raman microspectroscopy. TrAC, Trends. Anal. Chem. 2014, 53, 33.

(56) Yang, H.; Irudayaraj, J. Rapid detection of foodborne microorganisms on food surface using Fourier Transform Raman spectroscopy. J. Mol. Struct. 2003, 646, 35.

(57) Popov, K. I.; Pegoraro, A. F.; Stolow, A.; Ramunno, L. Image formation in CARS and SRS: effect of an inhomogeneous nonresonant background medium. Opt. Lett. 2012, 37, 473.

(58) Alkan, M.; Çelikçapa, S.; Demirbaş, Ö.; Doğan, M. Removal of Reactive Blue 221 and Acid Blue 62 anionic dyes from aqueous solutions by sepiolite. Dyes Pigm. 2005, 65, 251.

(59) Priya, M.; Gurung, N.; Mukherjee, K.; Bose, S. Microalgae in removal of heavy metal and organic pollutants from soil. Microb. Biodegrad. Biorem. 2014, 521. 